REVISTA DE DERECHO UNED, NÚM. 18, 2016

\title{
LA PROCLAMACIÓN DE CARLOS IV EN CUENCA COMO SÍMBOLO DE FIESTA Y PODER
}

\author{
THE PROCLAMATION OF CARLOS IV IN BASIN \\ LIKE SYMBOL OF HOLIDAY AND POWER
}

\author{
Eulogio Fernández CARRAsco \\ Profesor Contratado Doctor \\ Universidad Nacional de Educación a Distancia (UNED)
}

Resumen: La estrecha relación entre Fiesta y Poder, ha sido uno de los casos de la literatura jurídica que con demasiada frecuencia y del mismo modo invariable a lo largo de muchos años, ha sido tratado y trasladado al medio escrito por diferentes autores. Este trabajo nos pone en antecedentes de la importancia de este instrumento recogido para la confección y conocimiento de las estructuras y nombres de las personas que conformaban el conjunto de fiestas y programas en que estaba dividida la Proclamación de Carlos IV en España.

En relación a la localización material de nuestro objeto de estudio, hay que especificar que, dentro de los estudios, no consta en la actualidad una monografía exclusiva que aborde el examen de la Proclamación del citado monarca en Cuenca que se desarrolla en torno al siglo XVIII, tanto por los historiadores foráneos como por los propios historiadores locales referidos a Cuenca. Contemplándolo desde un punto de vista histórico-jurídico, para el estudio de este trabajo, hemos estudiado diversos manuscritos de la biblioteca Nacional y Archivo Histórico Nacional.

Abstract: The narrow relation between Holiday and Power, has been one of the cases of the juridical literature that too often and in the same way invariable throughout many years, it has been an agreement and moved to the way written by different authors. This work 
puts us in precedents of the importance of this instrument gathered for the confection and knowledge of the structures and names of the persons who were shaping the set of holidays and programs in which the Proclamation of Carlos IV was divided in Spain.

In relation to the material location of our object of study, it is necessary to specify that, inside the studies, there does not consist at present an exclusive monograph that approaches the examination of the Proclamation of the mentioned monarch in Cuenca that develops concerning the 18th century, both for the foreign historians and for the own local historians referred to Cuenca. Contemplating it from a historical-juridical point of view, for the study of this work, we have studied diverse manuscripts of the National library and Historical National File.

Palabras clave: Fiesta, Poder, Proclamación, Rey, Corregidor.

Keyword: Holiday, Power, Proclamation, King, Sheriff.

Recepción original: 11/02/2016

Aceptación original: 06/04/2016

Sumario: I. Introducción. II. Elementos. III. Actos preparatorios. IV. La Comitiva. V. Las preeminencias u orden en la Comitiva. VI. Traslado del Pendón. Actos religiosos y Jura al Príncipe. VII. Itinerario. VIII. Escenario. IX. Cabalgata. Ornato y regocijos. $\mathrm{X}$. Conclusiones.

\section{INTRODUCCIÓN}

En este trabajo, la palabra Noticia, la debemos entender como la expresión de la brevedad o exposición concisa de un texto o relato, que sirve para señalar las pautas fundamentales de una función, en este caso de las funciones llevadas a cabo en Cuenca durante los días veinte al veintiocho de mayo de 1790 en honor y con motivo de la Proclamación de Carlos IV en esa ciudad. Debemos hacer la salvedad, que en este estudio, la Noticia se confunde con la palabra Relación, ya que la fuente de donde se nutre, es un folleto breve de pocas páginas en el que no figura ningún grabado o imagen, a pesar de haber sido elaborado por la Imprenta Real de Madrid ${ }^{1}$.

${ }^{1}$ Sobre este trabajo, véase: BN. R/39600(38). Noticia de las Funciones executadas en la M. N y M. L. ciudad de Cuenca con motivo de la Proclamación del Señor Don Carlos IV en el día 20 de mayo de 1790. Madrid. 1790. Imprenta Real.

BN. R/39600(39). Relación de las funciones executadas por la Real Sociedad Económica del País de la ciudad de Cuenca en los días señalados por esta misma para la 
Otro tanto ocurre en cuanto a la utilización que tenemos necesariamente que concebir, al utilizar la palabra Crónica, al imaginarlo como el concepto de una narración llevada a cabo de forma reiterada en relación a un tipo de acontecimiento o acto, el cual, está sometido a la exposición reiterada de un programa de fiestas.

Por último, la Proclamación como instrumento que sirve para reflejar una Cédula Real o precepto real, el cual era exigido en los festejos en donde se producía la Jura al nuevo monarca, ya que en sí, la Proclamación era considerada como una especie de ceremonia obligatoria que necesariamente había de ser observada y cumplida por provenir de una orden real. La Proclamación, por tanto, la podemos considerar como el acto desarrollado por los estamentos de una ciudad, conducentes a la consecución de llevar a cabo la Jura del nuevo monarca, produciéndose como consecuencia de ello el obligado vasallaje. La Proclamación de Carlos IV en España dio lugar a ser considerada como el acontecimiento o acto más festejado en la España del siglo dieciocho.

\section{ELEMENTOS}

Desde nuestro punto de vista, los elementos o partes de que consta esta Noticia, las podemos diferenciar en dos clases, por un lado están las partes principales y por otro, las llamadas subsidiarias o complementarias, sin que ello agote la existencia de otras. Respecto a las primeras podemos destacar tres fundamentales: 1. La Jura, que es la parte esencial de la Proclamación. 2. El levantamiento del Pendón Real y 3. Los retratos de los reyes y príncipes. En cuanto a las segundas o subsidiarias, podemos destacar entre varias a: 1. Los ornatos. 2. La cabalgata. 3. Los regocijos. La narración de los ornatos, no es objetivo principal de la Noticia, pues no es una parte fundamental o pauta de la función, como ya se dijo antes.

Para el desarrollo del presente estudio, y por una cuestión práctica, las fases las hemos titulado: 1. Actos preparatorios. 2. La comitiva. 3. La preeminencia u orden de la comitiva. 4. El traslado del

augusta aclamación de nuestro rey el Señor D. Carlos IV. Real Sociedad Económica de Amigos del País de Cuenca. Madrid. 1790. Imprenta Real.

Mercurio Histórico y Político. Agosto. 1790. Tít. Cuenca 20 de julio. Tomo II. Pp. 363-365. Madrid. 1790. Imprenta Real.

Memorial literario, instructivo y curioso de la corte de Madrid. V. 20. Mayo de 1790, parte segunda, n. ${ }^{\circ}$ CX. Madrid. Editorial Imprenta Real. 1789-1808. 
Pendón o Estandarte real. 5. El itinerario. 6. El emplazamiento y 7. Cabalgata. Ornatos y regocijos.

\section{ACTOS PREPARATORIOS}

Comienza el relato dando muestras de arrepentimiento por la tardanza en llevar a cabo los actos de Proclamación de Carlos IV en esa ciudad conquense. Muestra el lamento de la ciudad, al decir que puesto que siempre había sido de las primeras en acreditar celo, amor y respeto a los reyes, sufría por tanto de forma impaciente, que en medio de tantas demostraciones de júbilo que se habían llevado a cabo en toda la nación, se retardasen las suyas, a pesar de la actividad con que se trabajó en prepararlas.

Para la fijación de los diferentes actos, fiestas y nombramientos de autoridades, se celebraron diferentes juntas extraordinarias presididas por el Corregidor para acomodo de las conducentes al método y buen orden con que habían de acordarse las demostraciones de regocijo. Fueron nombrados por Comisarios los Regidores perpetuos, Francisco Paula Castillo Álvarez de Toledo, Maestrante de Ronda y a Santiago Guzmán de Villoria, Alguacil mayor del Santo Oficio de la Inquisición, Teniente Coronel del Regimiento Provincial. También fue señalado el día 20 de mayo para llevar a cabo la Real Proclamación y los sucesivos hasta el día 28 , respecto a los festejos.

El pensamiento del Corregidor Juan Antonio Serrano y Cieza, estaba centrado en creer que la época de haber ocupado el trono un rey, a quien sobre todas las demás regias virtudes, caracterizaban por un lado el amor a sus pueblos y por otro, la beneficencia, debía señalarse no solo con festejos momentáneos en que las ansias de un pueblo fiel se desahogan con aclamaciones y júbilos, sino con obras permanentes útiles a la patria y decorosas a una capital tan recomendable, amén de perennes monumentos que recordasen a la posteridad una idea tan feliz y memorable.

A consecuencia de las órdenes que obtuvo y para poder llevar a cabo tan solemne acto, emprendió la tarea de suavizar la aspereza de las calles principales por donde debería transitar los festejos con rebajes considerables de ellas y quitar además la deformidad de sus voladizos, que impedían la ventilación y las luces. No se creyó al principio que hubiese que vencer otras dificultades que las que ofrecía la propia naturaleza, pero no dejaron de presentarse dificultades e inconvenientes que se presentan en todos los proyectos útiles, que 
sólo desvanece la constancia y el práctico convencimiento y que llevan a su feliz término.

Se rebajaron en la calle que iba desde la cárcel baja hasta San Juan, la cantidad de 123,219 pies cúbicos de piedra viva de los 1152 que componían su distancia, dejando el piso bien empedrado con losas márgenes y tan suave, que con facilidad podía circular un coche tirado por dos mulas, ya que antes, no se podía transitar uno con un solo tiro. Iguales ventajas recibieron los ramales que bajaban al Oratorio de San Felipe y a la parroquial de San Andrés, consiguiendo aumentar los edificios de una y otra acera, las habitaciones de que carecían antes y además conseguir que desapareciesen las humedades.

Por el mismo orden se allanaron y empedraron la Plaza Mayor, la calle del Juego de Pelota viejo, la que del cuartel de Milicias que iba hasta la Puerta de Valencia, la que de ésta subía a San Vicente y otras que por no dilatar la real proclamación, debían después continuarse para perfeccionar el proyecto que se propuso el Corregidor, consiguiendo que un pueblo notoriamente desagradable por su aspereza y empinadas calles, quedase en el número de los más cómodos y buen aspecto de la monarquía. A este fin y conducido de su celo al público, demolió una casa que deformaba e impedía el libre uso de la calle de San Juan Baja hasta Santo Domingo, pagando su legítimo valor al dueño de la finca; todo a su costa y a la del Regidor don Francisco Paula Castillo, que voluntariamente contribuyó con su parte a tan laudable objeto.

\section{LA COMITIVA}

Transcurría el día 20 de mayo y aún a pesar de no ser la tarde muy apacible, pues llovía intensamente, y dado que la tropa del Regimiento Provincial se hallaba reunida con sus Jefes militares y bandera y habiendo sido convocado un numeroso concurso de naturales y forasteros, no se detuvo la Ciudad para verificar el acto, y tomando los caballos se ordenó la comitiva. La uniformidad de esta lúcida comitiva, el bello gusto de los jaeces y encintado de los caballos, la brillantez con que se presentaron los criados y el buen orden observado, correspondieron al decoro y majestad de un acto tan respetable.

Sacó el Corregidor el nuevo Real Pendón de damasco carmesí, el cual estaba bordado de oro, con flecos, cordones y bolas de lo mismo. Una vez precedidas los rituales de costumbre, hizo formal entrega al Regidor Decano Juan Nicolás Álvarez de Toledo, conde de Cervera, 
que en defecto del Alférez mayor debía levantarle; y formada la Ciudad en dos filas de individuos, puestos de ceremonia, siendo acompañada del Coronel de Milicias y del Ejército don Julián Guzmán de Villoria como Regidor de Madrid, que además lo hacía por serlo de ciudades con derecho a voto en Cortes y de los que aunque retirados sirvieron los mismos oficios en ella.

Componían el cortejo también los títulos de Castilla nombrados para este y demás actos, los cuales estaban distribuidos en sus respectivos puestos y todos vestidos de ceremonia con casco y casaca de terciopelo sin cortar, chupas y vueltas de glasé de plata, bordadas de oro y piedras, sombreros con plumajes, presillas de brillantes, medias y guantes blancos. Salió el séquito de las Casas Consistoriales precedida de clarines y timbales ${ }^{2}$ con los Maceros. En medio de aclamaciones y repique general de campanas, sueltos los relojes de Mangana y el de la Santa Iglesia Catedral se dirigió la comitiva a la Catedral.

En las Casas Consistoriales figuraban las siguientes inscripciones

\section{Alfonsus VIIIs}

Concham

Sarracénica tirannide appresam, et afflictam

Armis in libertantem asservit

\section{Carolus IV}

Virtutibus, quibus et famam

Et Summam de se expectationem vincet

Veteri splendori restitute

Non sic excubiae, nec circunstantia pila

Quam tutatur amor. Carolum tutatibur ille,

Hoc alterna fides, hoc simplex gratia donat Adspice nunc, quacumque micas, seu circulus Austri

Magne parens gelidi, seu te meruere Triones.

Adsoice completum votum, jam ntus adaequat

Te meritis, et quod magis est optabile vincet

Huic ego, nec metas rerum, nec tempora pono

Imperium sine fine dedi.

Fue recibida la comitiva por el pleno del Cabildo con capas de coro, teniendo a su cabeza a su dignísimo Prelado vestido de Pontifical. Una vez hechas las reverencias regulares por uno y otro cuer-

${ }^{2}$ Instrumentos musicales militares considerados como símbolos de los triunfos del nuevo Rey. 
po, siguieron procesionalmente hasta la Capilla Mayor, llevando siempre el Corregidor a su derecha al conde de Cervera con la Real Insignia. Ocupado el Coro por el Cabildo y su sitio preeminente por la Ciudad, hicieron oración. Puestos todos en pie y su Ilustrísima en el Presbiterio bajo dosel, uno de los Canónigos asistentes condujo el Real Pendón para bendecirlo con las oraciones rituales. Una vez finalizado, se adelantó el conde e hincado de rodillas en la almohada delante del Prelado, lo recibió con ósculo de paz y ejecutando lo mismo con él hasta el Estandarte, lo tomó, se retiró a su puesto y saliendo el Cabildo a despedir a la Ciudad en los términos que a su entrada, se restituyó a sus Casas Consistoriales y una vez en ellas, devolvió el Pendón al Corregidor y depositado por él bajo dosel, finalizó el acto y a las tres y media de la tarde se juntaron los Capitulares en el Consistorio.

Por un lado, salió de sus Casas pretorias el Corregidor a caballo primorosamente enjaezado, llevando delante de él, seis Ministros de golilla, al Alguacil mayor, el Teniente de Alguacil mayor a caballo, dos volantes ricamente vestidos con las divisas de su librea, guarnecida de glasé de plata, flecos de los mismo, flores de Italia en las gorras con los escudos de sus armas. Llevaba detrás dos lacayos con libreas de gala y caballos de mano cubiertos de reposteros guarnecidos de gasas y flecos de plata, con los escudos de sus armas. Al llegar a las Casas Consistoriales, desmontó y subió al puesto que le correspondía.

Por otro lado, salió también el conde de Cervera de las suyas a las cuatro a caballo, bien enjaezado con la debida forma y precedido de los Gremios con sus dos volantes y acompañado de varios Caballeros convidados para que le acompañaran. Iban también dos Regidores que pasaron a conducirlo, todos a caballo, y por último, cerraban dos de respeto llevados de la brida por lacayos con libreas de gala. Una vez que llegaron a las Casas Consistoriales, subieron a las antesalas, se dio aviso a la Ciudad y siendo recibido por otros dos Comisarios en las salas Consistoriales, repitió el Corregidor la entrega del Real estandarte con las ceremonias de costumbre.

El día 21 por la tarde salieron los Gremios en comparsas figurando la toma de Cuenca y entrada en triunfo del rey don Alfonso VIII, que conducido en un suntuoso carro, y acompañado de una vasta comitiva precedida de soldados a caballo, timbales y clarines, llegó a la Plaza y subiendo al tablado que sirvió para la Proclamación, ocupó su silla y almohada recibiendo la obediencia y homenaje que le prestaron todos con alusión al que se renueva en la persona de su majestad reinante, a quien de nuevo lo reconoce y jura por su soberano. 
Se personalizaron las villas conquistadas con las banderas de sus armas, ofreciendo sus peculiares frutos y esquilmos, que fueron las de los conquistadores, las Órdenes Militares que concurrieron, y cuanto condujo a su condecoración, guardando los rituales que los romanos hacían en semejantes actos.

El rey correspondió repartiendo las diferentes mercedes, gracias y privilegios concedidos a la Provincia, como también otros símbolos de su protección a la Religión, Ciencias y Artes, recitándose en verso por uno de los jefes del acompañamiento la relación de este pasaje de la historia.

Finalizado volvió rey a su carro triunfal; continuó la marcha con su comitiva, cerrándola el Teniente de Alguacil mayor con dos Ministros a caballo y otra partida de soldados, que dando vuelta a la carrera, concluyeron los festejos del día, repitiendo la iluminación general, repique de campanas y relojes, y la música en los balcones de la ciudad.

En la tarde del día 22 representaron los mismos Gremios la fábula Pandora y concilio de los Dioses tan conocida en la Mitología, principiando la numerosa y concertada comitiva como en el día antecedente, siguiendo las comparsas respectivas de los Dioses que se distribuyeron en cuatro primorosos carros triunfales costeados, el principal y muy superior por los Gremios y los otros tres por los Labradores y Hortelanos.

La Diosa Ceres iba coronada de espigas, con racimos de uvas y amapolas en una mano, en la otra, el asta de Amaltea, arrojando flores y frutos. Llevaba a los pies un dragón alusivo a cuando caminaba en busca de Proserpina, y componían su comparsa segadores y espigaderas. Le acompañaba Palas con morrión, el escudo de Medusa rodeado de serpientes, pica en la mano y a los pies el Mochuelo, animal que le fue consagrado, siendo su comparsa, filósofos y soldados.

Mercurio llevaba su Caduceo; Pegaso alas en cabeza y pies, otras insignias y delante el Gallo como característico. Apolo con corona de laurel, la lira y las serpientes a la espalda, carcax con arco y flechas y a los pies el cisne. Sus comparsas eran, la del primero, holandeses, chinos y otras nacionalidades de comerciantes; la del segundo orquestas de música y diferentes danzas con alusión a los juegos Pythios.

Vulcano con un gorro en la cabeza, tenaza y martillo en la mano, el Lebrel a los pies en memoria del que regaló a Júpiter; su acompañamiento Ciclopes, Ojancos y otros menestrales de Herrería, trabajando en una fragua alusiva a la del Etna. Júpiter con corona, cetro y manto imperial, el rayo en la mano y a los pies la Cabra que le está consagrada; componiendo su comparsa los Gigantes por haberlos vencido esta deidad. 
Al carro magnifico en que iba Pandora precedía una primorosa danza de enanos y su brillante comitiva, cerrando el Teniente de Alguacil mayor con dos Ministros y otra partida de Caballería. Al llegar al tablado, en el que como en el día anterior se hallaba la silla y almohada, bajaron los Dioses y esperando a Pandora la acompañaron a su puesto, y sentada la fueron ofreciendo sus respectivos dones, recitando en verso cada uno los justos motivos de su gratitud, todo con alusión a que si en aquella Diosa que sacó Vulcano tan perfecta admiraron y confesaron los demás su preferencia tributándole dones, con cuánta más razón debería Cuenca, su Provincia y el reino, respetar y reconocer a la reina su señora por su soberana, publicando las virtudes, gracias y dotes que la singularizan.

Concluido este acto circuló por la carrera toda la comitiva, continuaron por la noche la iluminación y repique general de campanas, habiendo retirado el Corregidor con el Ayuntamiento el Real estandarte después de tremolarle tres veces en los balcones y proferir por otras tantas viva al señor don Carlos IV nuestro soberano (que Dios guarde), en que concurrió el pueblo con sus filiales aclamaciones.

\section{LAS PREEMINENCIAS U ORDEN EN LA COMITIVA}

Las clases dirigentes siempre se situaban en lugares de privilegio y ocupaban un determinado lugar preeminente en los cortejos de Proclamación. Cuando ejercían como espectadores, los privilegiados se colocaban en sitios clave, desde donde podían ser fácilmente contemplados por el resto del público. En el aspecto ceremonial religioso, los miembros de los Cabildos, el Corregidor, Alguaciles mayores y Teniente, ocupaban bancos al lado del presbiterio, sin embargo el resto de los fieles veían la ceremonia de pie. Cuando estaban en la Plaza Mayor de Cuenca las autoridades locales se situaban en balcones y tablados especiales. En las ceremonias donde se tremolaba el Pendón, se solían poner asientos junto al tablado donde iba a ser proclamado Carlos IV, para que se situasen en ellos el Corregidor, el Deán y Canónigos de la Santa Iglesia Catedral, el Teniente, Alcalde Mayor, los oficiales y caballeros.

El orden en que situaba la Comitiva, era el siguiente:

a. Una vez formada la Comitiva, abría la marcha una partida de soldados de Caballería con espada en mano.

b. A continuación iban los Gremios vestidos a la española antigua, igualmente iban vestidos de moros, holandeses, húngaros y otros trajes, formando dos filas como era estilo. 
c. Los Ministros de justicia a caballo con golilla y varas altas.

d. El Alguacil mayor con su vara propia.

e. Los Porteros con mazas de plata, ropas talares de damasco carmesí guarnecidas de galón de oro, sombreros forrados en lo mismo y con gasas de oro colgantes.

f. El Mayordomo de la Ciudad.

g. Los Escribanos de Ayuntamiento.

h. El Procurador del Estado de Caballeros Hijosdalgo.

i. El Síndico Personero.

j. Los Diputados del Común.

k. Los Regidores.

1. Los demás convidados vestidos de ceremonia como en la mañana de aquel día, y cada uno con su volante al estribo ricamente adornado.

m. En el centro iban los Reyes de Armas con cotas de damasco carmesí bordadas de oro.

n. Cerrando este majestuoso cuerpo iba el Corregidor con bastón, situándose el conde de Cervera a la derecha con el Real Estandarte. Detrás iba el Teniente de Alguacil mayor con vara de justicia, los caballos de respeto de los dos antecedentes eran conducidos por sus respectivos lacayos y acompañaba otra partida de Caballería con espada en mano.

\section{TRASLADO DEL PENDÓN. ACTOS RELIGIOSOS Y JURA AL PRÍNCIPE}

El día 20, el Estandarte fue llevado a través de la ciudad conquense para poder llevar a buen fin la Jura de Proclamación. Normalmente, su salida se situaba en las Casas Consistoriales en donde las autoridades como eran el Corregidor y el Teniente de Alguacil mayor coexistían en las funciones de ser los encargados de portar el Pendón Real. Una vez restituida la comitiva a las Casas consistoriales, devolvió el conde de Cervera el Real Pendón al Corregidor y sacado por éste al balcón principal, lo tremoló tres veces, diciendo como era habitual en todas las Proclamaciones dedicadas a este monarca: viva el señor don Carlos IV (que Dios guarde). 
El día 21 por la mañana, habiéndose juntado la ciudad como en el día antecedente pasó en la catedral al Te Deum que celebró de Pontifical su Ilustrísimo Obispo con asistencia del Cabildo, en acción de gracias por la exaltación al trono del soberano, y para implorar de la divina omnipotencia derramase sus bendiciones sobre sus Majestades y Real Familia, concediéndoles toda prosperidad.

Igual acto de religión había ejecutado la Sociedad Patriótica de Amigos del País el día 19, teniendo exámenes públicos en que repartió varios premios asignados por su Ilustrísima, por el Corregidor, por los Regidores Francisco Paula Castillo y Santiago Villoria y por otros sujetos amantes de la buena educación y progreso de la juventud, de que, la misma Sociedad dio noticia individual y circunstanciada.

Un Canónigo de la propia catedral cuyo nombre no se publicó, vistió interior y exteriormente a 60 pobres de ambos sexos elegidos por los curas de las 14 parroquias de la ciudad, concurriendo a una misa solemne que se dijo en San Nicolás por D. Antonio López, su Párroco y al Ofertorio se adjudicaron dos dotes de 50 ducados que a expensas del mismo beneficio canónigo, fueron sorteados entre 16 niños y niñas para tomar estado, comulgando todos, y después de haber recibido decentes limosnas pasaron a la catedral a implorar las divinas piedades por intercesión de San Julián, cuyo cuerpo se expuso en su magnífica capilla por tres días de acuerdo de su Cabildo.

El día 23 por la mañana con la mayor pompa y aparato prestó el Obispo juramento en manos del Deán, y de la misma forma se rindió pleito homenaje en las del Corregidor al Príncipe don Fernando, celebrándose este acto tan decoroso en la Capilla de San Julián que existe en la Santa Iglesia catedral, teniendo después en su palacio un abundante y espléndido banquete.

Con tan plausible motivo dictó decreto este Prelado perdonando 286,393 reales que se le debían por distintos Labradores y Artesanos imposibilitados. Al mismo tiempo se consignó 50 dotes de 100 ducados para distribuirlos entre otras tantas doncellas honestas que fuesen del territorio de sus Mayordomías, a fin de tomar el estado de religión o matrimonio que eligiesen.

\section{ITINERARIO}

En el itinerario, había que destacar dos partes, una era la zona urbana como la más importante, la otra, con menos trascendencia, era la zona de extrarradio o arrabal. Generalmente salía de las Casas 
Consistoriales en donde el Corregidor y el Teniente de Alguacil mayor eran los encargados de portar el Pendón Real, y que usualmente era en la Plaza Mayor donde se producía o bien la primera o única Proclamación o bien tremolar ${ }^{3}$ el Pendón. En este caso que estudiamos, existía un segundo lugar, que era la Plaza de la Inquisición y para finalizar como tercer lugar era el emplazamiento, que recordemos era el Campo de San Francisco. En este caso, era el traslado desde la zona urbana de Cuenca al arrabal, ya que se produce desde las Casas Consistoriales hasta el Campo de San Francisco (en la actualidad se ubica la Diputación Provincial de Cuenca).

Se hallaban revestidas y adornadas las salas Consistoriales con damasco carmesí, medias cañas doradas, cortinajes, frisos correspondientes, los techos de pinturas al fresco, las puertas con remates dorados, dosel de terciopelo con galones y flecos de oro para los retratos de los reyes, canapés de igual clase y construido nuevo oratorio de estucos, columnas, altar y otros adornos del orden compuesto. Todo lo descrito, fue estrenado en la mañana del mismo día 20 de mayo, celebrando misa en el Oratorio su Capellán y que fue aplicada por la salud, acierto y felicidad de los soberanos. En este recorrido, es de resaltar el lucimiento de las fachadas tanto públicas como particulares. En este caso, por significar, podemos citar a las Casas Consistoriales conquenses en donde destacan las pinturas al fresco y adornos de orden compuesto.

Del estudio de la función que estudiamos, entendemos que el recorrido se produjo de la siguiente forma y dado que no aparece ninguna constancia de ello en el mencionado relato, aunque como se expuso al principio, las obras llevadas a cabo por orden del Corregidor, dan a entender que el arreglo de las citadas calles eran con objeto de poder realizar en ellas la procesión desde la Plaza Mayor hasta el Campo de San Francisco, lugar éste, elegido por la Inquisición de Cuenca para la ubicación del quemadero de los herejes relapsos. Por tanto podemos señalar las siguientes calles por donde se produjo el itinerario de la procesión por este orden: Plaza Mayor, calle del Juego de Pelota viejo, calle que discurría entre el cuartel de Milicias y la Puerta de Valencia, calle San Vicente, calle de San Juan Baja y Santo Domingo,

\section{ESCENARIO}

Con esto queremos significar lo que entendemos por tablado o escenario protocolario a donde subían el Corregidor, el Teniente de

\footnotetext{
${ }^{3}$ Agitar al aire una bandera, pendón o estandarte.
} 
Alguacil mayor y se tremolaba el Pendón y se gritaban los vivas. El tablado normalmente estaba adornado con balaustres, estatuas, pilastras, alfombras o tapices de terciopelo con columnas o estatuas de grandes dimensiones.

Generalmente, el itinerario se desarrollaba en tres partes llamadas actos. En este caso fueron:

Primer acto. El día veinte de mayo de 1790, la lúcida comitiva llegó a la Plaza Mayor, en donde formado el Regimiento Provincial uno enfrente del otro, batiendo la marcha, y presentando las armas a la Real Insignia, se dirigieron al tablado donde se colocó para celebrar el primer acto. Estaba custodiado por cuatro centinelas situados en sus ángulos. Además se adornó la circunferencia con balaustres, pirámides, jarrones, las Armas Reales y las de la Ciudad con dos órdenes de gradas. Igualmente estaba alfombrado todo y con inscripciones alusivas al asunto.

Dejando los caballos subieron los Maceros, los Escribanos de Ayuntamiento, los Reyes de Armas, el Regidor Sub decano Antonio del Castillo y Peralta, el Corregidor y el conde de Cervera, y colocados en el centro éste a la derecha y el Corregidor a la izquierda y el Sub decano mirando de frente a las Casas Consistoriales. Una vez impuesto silencio por los Reyes de Armas, se pronunció la fórmula de: Castilla, Castilla, Castilla por el señor rey don Carlos IV (que Dios guarde) tremolando tres veces el Real Pendón. Ocurrido lo anterior, en el mismo momento se quitaron todos los sombreros, fue descorrida la cortina que cubría los balcones consistoriales bajo magnífico dosel de terciopelo carmesí y galones de oro, en donde estaban los reales retratos de los Reyes y custodiado por dos granaderos del Regimiento Provincial con bayoneta calada, que pertenecían a la compañía que destacó el Coronel para prestar los debidos honores. Esta guardia permaneció tres días y sus correspondientes noches, permaneciendo en esta forma.

En ese preciso momento, dio comienzo el repique general de campanas a vuelo, se soltaron los relojes, y conmovido el pueblo con el gozo de su fidelidad, prorrumpió en repetidas vivas y aclamaciones; y en el que se arrojaron varias monedas de plata, dispuestas para este fin por el conde de Cervera.

Los Comisarios de la Proclamación, pensaron que como el ingenio, la erudición y el gusto en las buenas letras, deben solemnizar tan gloriosos auspicios del reinado en que han de tener sus mayores progresos, en una lengua que a juicio de todos los sabios, conserva todavía con la majestad del Imperio que la hablaba, la fuerza, energía y aptitud a que no habían llegado los vulgares de Europa, se repartie-

(C) UNED. Revista de Derecho UNED, núm. 18, 2016 
ron en las fachadas y decoraciones con que singularizó Cuenca la Real Proclamación. Para ello, optaron por poner inscripciones en latín en diferentes lugares de Cuenca.

En el tablado de la Plaza Mayor aparecía la inscripción siguiente:

Carolo IV et Aloisiae Augustis

Civ. Conch

Qua semper firma fide

Jugique studio, qtque obsequio

Suos Reges

Coluit, et observavit

Iisdem ubi opus fuerit

Sedulis, atque amore profectis officiis

Praesto adfore pollicetuur

Redeunt Saturnia Regna

Segundo acto. Con el mismo orden siguió la comitiva a reiterar iguales actos en la Plaza de la Inquisición y el Campo de San Francisco, dirigiéndose por las calles señaladas al intento. En uno y otro significó el pueblo su alegría, dando pruebas de su gozo y fidelidad como al principio.

En la Plazuela de la Inquisición rezaba la siguiente inscripción:

Non despecta tibi fuero si quaeris Alexi Quam dives pecoris nivei, quam lactis abundanns

Mille greges errant per montes quos tibi servo

Avita erga suos Reges, et ubique locorum

Impolluta Hispanorum fides

Asperrima montium juga libentius incolit

Et cum integris adhuc, et incorruptis

Durorum monticolarum moribus

Melius congruity

En el Campo de San Francisco, se configuró el río Júcar en persona humana, levantando las manos y con el ánfora o cántara y la siguiente inscripción:

Sucro pater caput extollit

Et protensis manibus

Oestro fatidico

Fausta, et laeta omnia

Sub Carolo, et Aloisia

Videtur praesagire. 
Tercer acto. Restituida la comitiva a las Casas consistoriales, devolvió el conde de Cervera el Real Pendón al Corregidor y sacado por éste al balcón principal, lo tremoló tres veces, diciendo: viva el señor don Carlos IV (que Dios guarde) y fue coocado en un primoroso pie construido con las Armas de la Ciudad para sostenerle bajo dosel, entre los retratos y centinelas. Finalizado lo anterior, acompañaron todos a caballo al conde de Cervera a su casa, produciéndose la retirada de todos los componentes a la suya.

\section{CABALGATA. ORNATOS Y REGOCIJOS}

El día 20 se produce un repique general de campanas y relojes que fue al oscurecer, principió la iluminación de la Ciudad y la música en los balcones consistoriales durando hasta las 11 de la noche. Aquella noche se sirvió en casa del conde de Cervera un magnífico y delicado refresco de varios géneros de helados, dulces de ramillete y demás; al que concurrió por convite el Obispo, el Corregidor, el Ayuntamiento, las Dignidades, Canónigos, Racioneros y medios Racioneros de la Santa Iglesia catedral, los curas, Beneficiados, los Prelados de los conventos, el Coronel de Milicias con toda la oficialidad, el Intendente, toda la Nobleza de ambos sexos tanto naturales como forasteros, los Jefes y dependiente de las oficinas reales, y después de una completa orquesta de música siguió el baile hasta el día, pasando de mil personas las que asistieron a este festejo.

Toda la casa estaba iluminada desde el portal, escaleras, corredores y salas. También estaba adornado el patio con arcos de murtas y figurando una especie de cenador con festones dorados. Y en el centro, se levantó una pirámide de trasparentes, que con muchas luces de colores repartidas en la circunferencia causaba bello aspecto. La fachada y otra casa pertenecientes al conde, no eran menos vistosas, pues estaban cubiertas con bastidores, transparentes, pirámides y otros adornos, teniendo en el centro los retratos de los Reyes bajo dosel y todo bien iluminado.

A las fachadas de estas casas, sustituyeron otras de imitada fábrica con columnas, pilastras, cornisas, dorados los capiteles y basas con remates primorosos. En los ángulos dos leones rampantes, sobre la cúpula estaba situado el escudo de las Armas Reales sostenido por dos estatuas alegóricas, todo del orden compuesto y remataba con orlas de faroles diversos, que con la simétrica distribución de hachas, morteretes, multitud de luces, y trasparentes, presentaba un delicioso 
objeto, hallándose repartidas en varios tarjetones las inscripciones latinas que dispuso el Corregidor.

Otras dos se pusieron en cada tablado de los construidos para los actos de Proclamación, iluminándose igualmente todos ellos con crecido número de luces de diferentes colores, que con las llamas arrojadas por las bocas de los jarrones situados en los cuatro ángulos, daban perfección al mérito de estas decoraciones.

En competencia se esmeraron todos los vecinos en los adornos e iluminación de sus respectivas fachadas queriendo con sencilla y fiel emulación, singularizarse en los obsequios a su soberano, pero entre todas sobresalieron las siguientes:

La fachada del palacio del Obispo, vestida de damasco carmesí, espejos, cornucopias doradas, magníficas arañas de cristal, pabellones en los balcones que estaban colocados en el centro bajo dosel de terciopelo, los retratos de los Reyes y todo remataba en un figurado corredor. Puestos en proporcionadas distancias varios jarrones sobre basas, de los que salían llamas luminosas, con las de un crecido número de hachas de cuatro pabilos a más de las velas en las cornucopias y arañas que entre todo, completaban la total y vistosa iluminación. Hay que añadir además, que durante la cual tocó la música religiosa en el tablado que se levantó a este fin.

La fachada del Corregidor observaba el orden jónico, con columnas y pilastras de imitados jaspes, dorados los capiteles y las basas. En los intermedios, había obeliscos de transparentes y otros varios adornos, teniendo en el centro del balcón general los retratos de los Reyes bajo un magnífico dosel. Sobre el pórtico las armas del Corregidor y la estatua de España, de cuyas manos pendían enlazadas de cintas de oro dos grandes tarjetas con inscripciones latinas, leyéndose otras cuatro en los zócalos de los obeliscos, estando dirigidas una al Rey, otras a la Reina y al Príncipe. Estaba rematado este cuerpo de arquitectura con las Armas Reales en la cornisa. Las orlas de diferentes faroles, la simetría en la colocación de hachas, morteretes y vasos y el excesivo número de luces, produjeron con la variedad de colores y transparentes una agradable y primorosa perspectiva.

En las Casas del Corregidor pendía en la estatua de España la siguiente inscripción:

Haec durissimos Milites

Haec experientissimos Duces

Haecfacundissimos Oratores

HaecClarissimos Vates parit 
HaecJudicim mater, haec Principum est

Haec Trajanum illum, haec Hadrianum

Haec te tandem

Carole

Haec tot alios praeclarissimos Principes

Dedit Imperio

Haec generat qui cuncta regant. Nec laude vivorum

Censeri contenta fuit, nisi matribus aeque

Vinceret et gemino certaret splendida sexu

Luov. Hisp. Reginae Aug.

Talem nulla refert antiquis página libris

Nec latiae cecinere tubae, nec graeca vetustas

Conjuge digna suo, nam tantum coetibus extat

Foemineis, quantum supereminet ille maritos.

Fern. Astur. Princ.

Cedat his terris terra Cretensis

Parvi Jovis gloriata cunabulis

Et geminis Delos reptata numinibus

Et alumno Hercule nobiles Thebae

Fidem constare nescimus auditis.

Te dedit Hispania, quem videmus.

Maxima sub optimo Principe virtus

Et Justitiam colere, et suum cuique reddere

Et sontibus poenas.

Et bonis praemia rependere

Tarda sit illa diez, et nostro serior aevo

Qua caput augustum, quem temperat orbe relicto

Perveniat virtus quo se sua ducit auntem

El Cabildo de la Catedral se esmeró en el ornato e iluminación de las Casas y galería que le pertenecían en la Plaza, vistiéndolas de buenas tapicerías, damascos, cornucopias y espejos.

Los Comisarios de la ciudad Francisco de Paula Castillo y Santiago Guzmán de Villoria, que residían en las de sus respectivos padres, adornaron con primor sus fachadas. Baltasar del Castillo Frías y Haro, que lo era del primero, figuró en la suya unos baluartes con sus torres y almenas, que ocupaban el primer cuerpo. Cubrió el segundo de lanzones pintados al temple con buen orden de arquitectura, colocando en el centro un pabellón con corona imperial, y la cornisa se orló de faroles, distribuyendo con dirección muchas luces de diversos colores. Julián Guzmán de Villoria, que lo es del segundo, levantó un jardín, cenadores, fuentes, pirámides, transparentes, un pabellón en 
el centro con manto y corona imperial, donde puso los retratos de los Reyes. Se iluminó todo en dibujo y tocó la música de su Regimiento en los tablados que se formaron con este objeto.

Las de Juan José Tenajas, Francisco Enrique del Río y Antonio del Rosal y Bolaños, Dean y Canónigos de la Santa Iglesia fueron de las más lúcidas, tanto en el buen gusto de sus adornos, cubriéndolas de damascos, pabellones, Casas de plata, cornucopias y otros, como por el crecido número de luces simétricamente colocadas y dispuestas. Antonio del Rosal colocó a su costa en la fachada de la Real Casa de Expósitos, varias serafinas, paño azul y lienzos, destinándolos para que después se invirtiese en un vestuario completo de los niños y niñas.

El Canónigo José Clemente Arestegui, adornó la perteneciente al mayorazgo de su sobrino Antonio José por estar ausente, con lanzones pintados, pabellones, pirámides, varias piezas de arquitectura, remates de luces, faroles y transparentes.

El seminario de San Julián acreditó su buen gusto en lo serio y decoroso de su fachada, siendo de las más vistosas en su iluminación, poniendo una inscripción alusiva al asunto.

Los padres mercenarios procuraron superarse en lo mismo, no siendo menos en las de sus respectivos conventos, los padres Carmelitas Descalzos y Trinitarios Calzados.

La Real Casa Hospital de Santiago se particularizó en la buena colocación de trasparentes, faroles y luces entre varios dibujos de arrayanes.

Los religiosos Franciscos construyeron en su atrio un jardín con arcos y cenadores, figurando en su pórtico otro de lanzones pintados, que con varios faroles, acreditaban el buen gusto del inventor.

El Número de Escribanos, Notarios y Procuradores, levantaron a su costa en el atrio de la iglesia de Trinitarios un elevado obelisco con su pedestal, colocando en los extremos remates de trasparentes, todo en buena proporción de arquitectura, que iluminado hacía una vistosa perspectiva.

Los Mercaderes y Comerciantes construyeron en la Correría un magnífico arco de orden compuesto, teniendo en la cornisa su balaustrado y por remate un Mundo sobre el que colocaron la estatua de la Fama, distribuyendo con buena dirección diferentes luces y transparentes.

Los Tenderos formaron otro arco frente al convento de padres Agustinos, que iluminado no era inferior al de los Comerciantes. 
Es de reseñar igualmente, los actos de caridad que llevaban a cabo los detentadores del poder. En la relación se nos informa de que el día 20 de mayo dio la comida el Corregidor a 73 pobres encarcelados con verdadera abundancia y esplendidez, encargándoles pidiesen a Dios por la salud, acierto y prosperidad de sus Majestades y la Real Familia. Los cuatro días siguientes, hicieron igual caritativa demostración el Obispo, el Arcediano titular de la Santa Iglesia catedral Antonio Palafox y Croy, el conde Cervera y la Junta de Ganaderos.

El día 22 y sin intermisión, principiaron los conciertos que la Ciudad dispuso en sus salones Consistoriales y baile público sin ceremonia, franqueando la entrada a toda persona de ambos sexos que se presentó con decencia sin capa ni mantilla y en términos que desdijese de una concurrencia tan ilustre, observando aquel modo, compostura y circunspección propia de tan serio y decoroso festejo. Estuvo presente el Corregidor y fueron Directores del baile que se ejecutaba un tiempo en tres salas el Regidor Francisco Antelo Pazos y Villoria con los de Proclamación. Se iluminaron vivamente la entrada, escaleras y salones, sin que en tan numeroso concurso se fomentara la menor confusión ni desorden.

El día 23 por la tarde se corrieron parejas por los Gremios en caballos de pasta en la Plaza Mayor, divididos en cuatro cuadrillas con distintos trajes y divisas e hicieron evoluciones, juegos de estafermo y sortija que concluyeron con las regulares a los reales retratos.

El día 24 se permitió que saliesen por la tarde los vecinos con mojigangas arbitrarias, divirtiendo al pueblo con lo extraño de sus disfraces e invenciones. En la misma se ejecutó sus habilidades en la Plaza del Campo de San Francisco una compañía valenciana, repitiendo la Ciudad por la noche sus conciertos y baile sin ceremonia como el día anterior, que continuaron después por dos días a costa de los Comisarios de Proclamación, para que el pueblo siguiese dando pruebas de su amor y regocijo en honor de los soberanos.

Los días 25, 26 y 28 se tuvieron por la mañana y tarde las tres corridas de novillos, permitidas por la superioridad en la plaza construida al intento, llenando el gusto y diversión de los aficionados.

\section{CONCLUSIONES}

El elemento fundamental en la proclamación es la comitiva en donde se fija un itinerario a través de la ciudad y cuyos componentes fijan los modelos ceremoniosos del acontecimiento o aclamación real y en donde se describe igualmente el cuadro lúdico y artístico de la 
fiesta. Esta comitiva esta detallada en el número de los integrantes, cargos, vestimenta e siempre de forma indefectible, los cargos que ocupan, los nombres y sus apellidos. Como siempre se describe, la comitiva está compuesta de un cortejo militar y civil.

El esqueleto que se podría diseñar en este caso, es que el cortejo comenzaba en las Casas Consistoriales al frente de un Corregidor y un Alguacil mayor o Teniente, con la misión de llevar el Pendón Real. Después se caminaba a la Plaza Mayor, se ejecutaba la primera Proclamación o tremolación del Pendón. A continuación y acto seguido de la primera Proclamación, el séquito se dirigía al segundo lugar y después de éste al tercer escenario haciéndose la Jura en todos ellos. También era normal que la Iglesia bendijese el Pendón Real y pasara por la Catedral, ya que el clero sigue siendo fundamental en los preparativos de la fiesta de Proclamación.

La función básica y fundamental del séquito era la de trasladar el Pendón Real a través de la ciudad para la Jura. En este caso que se estudia, se jura al Rey, pero también al Príncipe. La Jura al monarca por la ciudad de Cuenca, fue el acto fundamental de la Proclamación, el colofón de la comitiva y el origen de las fiestas.

El itinerario fijado por plazas y calles en su recorrido fue un asunto fundamental. De forma obligada se elegía la zona ilustre de la ciudad, próxima con edificios oficiales, espacios amplios y plazas transitadas y conocidas en la ciudad. Además de buscar a propósito la proximidad de palacios y casas nobles que estaba integrada en los cortejos, dando lugar a que sus propietarios se lucieran en la ornamentación y decoración de sus propiedades. Para evitar la irregularidad y estrechez de las calles, en Cuenca, las autoridades civiles y religiosas, reforman y amplían calles y casas para hacer más esplendoroso el cortejo.

El poder convocante de la Proclamación hace que la comitiva atraviese de forma intencionada palacios, iglesias, conventos, mercados, plazas y arrabales. La Proclamación de Carlos IV se lleva a cabo en la Plaza Mayor (en los balcones del Ayuntamiento de Cuenca), luego en la plazuela de la Inquisición y después en el campo de San Francisco durante los días 20 a 22 de mayo.

En cuanto al ornato empleado aquí, se relata la instalación de tapices y colgaduras en las fachadas, luces e inscripciones en las fachadas. Se trata de resaltar el lucimiento y la decoración que presentaron las fachadas del Ayuntamiento, Obispado y casas de la nobleza.

En síntesis, la Proclamación como símbolo de poder y fiesta, hay que entenderla como un acto protocolario. 